ARTICLE

Received 31 Jul 2015 | Accepted 19 Oct 2015 | Published 18 Nov 2015

DOl: $10.1038 /$ ncomms 9932

OPEN

\title{
Low-temperature-processed efficient semi-transparent planar perovskite solar cells for bifacial and tandem applications
}

Fan Fu', Thomas Feurer ${ }^{1}$, Timo Jäger ${ }^{1}$, Enrico Avancini ${ }^{1}$, Benjamin Bissig ${ }^{1}$, Songhak Yoon², Stephan Buecheler ${ }^{1} \&$ Ayodhya N. Tiwari ${ }^{1}$

Semi-transparent perovskite solar cells are highly attractive for a wide range of applications, such as bifacial and tandem solar cells; however, the power conversion efficiency of semitransparent devices still lags behind due to missing suitable transparent rear electrode or deposition process. Here we report a low-temperature process for efficient semi-transparent planar perovskite solar cells. A hybrid thermal evaporation-spin coating technique is developed to allow the introduction of PCBM in regular device configuration, which facilitates the growth of high-quality absorber, resulting in hysteresis-free devices. We employ high-mobility hydrogenated indium oxide as transparent rear electrode by room-temperature radio-frequency magnetron sputtering, yielding a semi-transparent solar cell with steady-state efficiency of $14.2 \%$ along with $72 \%$ average transmittance in the near-infrared region. With such semi-transparent devices, we show a substantial power enhancement when operating as bifacial solar cell, and in combination with low-bandgap copper indium gallium diselenide we further demonstrate $20.5 \%$ efficiency in four-terminal tandem configuration.

\footnotetext{
${ }^{1}$ Laboratory for Thin Films and Photovoltaics, Empa-Swiss Federal Laboratories for Materials Science and Technology, Ueberlandstrasse 129, 8600 Duebendorf, Switzerland. ${ }^{2}$ Laboratory for High Performance Ceramics, Empa-Swiss Federal Laboratories for Materials Science and Technology, Ueberlandstrasse 129, 8600 Duebendorf, Switzerland. Correspondence and requests for materials should be addressed to F.F. (email: Fan.Fu@empa.ch) or to S.B. (email: Stephan.Buecheler@empa.ch).
} 
$\mathrm{T}$ he emerging perovskite solar cells have received increasing attention due to the high efficiency, easy processing and potentially low $\operatorname{cost}^{1-2}$. Although the power conversion efficiency of perovskite solar cells have soared up to $20.1 \%$ (ref. 3), there is still ample room for further efficiency improvement through novel concepts ${ }^{4-6}$. An effective approach to increase the efficiency and lower the production cost is to make semi-transparent solar cells that can convert solar energy into electricity from both front and rear side of the device ${ }^{7}$. The bifacial cell concept has been implemented in various kinds of solar cell technologies ${ }^{8-12}$, and up to $50 \%$ output power enhancement has been demonstrated in Si wafer bifacial modules by collecting the albedo radiation from surroundings ${ }^{13}$. In addition, the semi-transparent perovskite solar cells hold great promise for applications in tandem solar cells ${ }^{14}$, photon energy upconversion ${ }^{15}$, building-integrated photovoltaics ${ }^{16}$, wearable electronics ${ }^{17}$, powering sensors and electronic gadgets in homes.

There are still many challenges hindering the realization of high-performance semi-transparent perovskite solar cells. The state-of-the-art perovskite solar cells ${ }^{3,18-22}$ employ high-temperature-processed $\left(\sim 500^{\circ} \mathrm{C}\right) \mathrm{TiO}_{2}$ (mesoporous and compact) as electron transporting layer (ETL), which is incompatible with monolithic tandem or flexible solar cells on plastics. Thus, it is desirable to develop a planar structure that allows low-temperature processing. It is well known that perovskite solar cells, particularly in planar configuration with $\mathrm{TiO}_{2}$ as ETL, suffer from pronounced hysteresis in the current density-voltage $(J-V)$ curve, which often results in overestimated device performance ${ }^{23}$. Therefore, it is imperative to eliminate the hysteresis, which is not only important to ensure a stable performance but also to unambiguously evaluate the real device efficiency. [6,6]-phenyl- $\mathrm{C}_{61}$-butyric acid methyl ester (PCBM) has been proven to assist in eliminating the $J-V$ hysteresis in inverted device configuration ${ }^{24}$. Several efforts have been made in positioning PCBM in regular device structure; however, the hysteresis phenomenon still remains ${ }^{25,26}$. For bifacial and tandem solar cell applications, it is crucial to replace the commonly used metal contacts in perovskite cells by highly transparent conducting electrodes, which allow sunlight incident from front and rear side of the device and to transmit the photons with energy below the bandgap of the perovskite. Previously, thin layers of $\mathrm{Au}$ (ref. 27), carbon nanotubes ${ }^{28}$ and PEDOT:PSS ${ }^{29}$ have been explored as transparent contact for perovskite solar cells, while the efficiencies are generally below $10 \%$ and these contacts featured strong absorption in near infrared (NIR). Efficient semi-transparent devices have been realized with graphene rear electrode; however, all the devices show strong hysteresis in current density-voltage curves ${ }^{30,31}$. Recently, sputtered transparent conductive oxides (TCO), including indium tin oxide (ITO) ${ }^{32}, \mathrm{ZnO} \mathrm{Al}^{33}$ and indium zinc oxide $(\mathrm{IZO})^{34}$, have been reported with highest efficiency of up to $12.1 \%$ for a semi-transparent cell and $19.5 \%$ in perovskiteCIGS (copper indium gallium diselenide) four-terminal configuration $^{33}$. Bailie et al. ${ }^{35}$ developed a $12.7 \%$ efficiency semitransparent perovskite solar cell employing Ag nanowires, and demonstrated 18.6 and $17 \%$ tandem efficiency by combining with CIGS and low-quality silicon bottom cell, respectively. Despite the high NIR transparency and low sheet resistance of Ag nanowires, the complicated deposition method leads to large efficiency variation and poor reproducibility, and the fast diffusion of $\mathrm{Ag}$ into Spiro-OMeTAD and perovskite results in degradation of device stability and performance ${ }^{36}$. Therefore, the implementation of a suitable transparent electrode material and deposition process is the key and challenge to high-efficiency semi-transparent perovskite solar cells. An ideal transparent electrode for perovskite solar cells should meet the following requirements: superior transparency in visible and NIR region, low sheet resistance, robust adhesion, good chemical stability and compatibility with adjoining layers. As the perovskite and SpiroOMeTAD are temperature and solvent sensitive ${ }^{35}$, a lowtemperature and dry process would be favoured for the deposition of transparent electrodes. In this regard, the roomtemperature sputtering deposited TCO would be an ideal candidate.

Here we report a low-temperature $\left(\leq 50^{\circ} \mathrm{C}\right)$-processed hysteresis-free high-efficiency semi-transparent planar perovskite solar cell. The hysteresis is eliminated through a PCBM interlayer and high-quality perovskite absorber enabled by the hybrid thermal evaporation-spin coating method. High-mobility hydrogenated indium oxide $\left(\mathrm{In}_{2} \mathrm{O}_{3}: \mathrm{H}\right)$ is employed as transparent rear electrode through a room-temperature radio-frequency magnetron sputtering, which enables a semi-transparent device with steady-state efficiency of $14.2 \%$ and $72 \%$ average
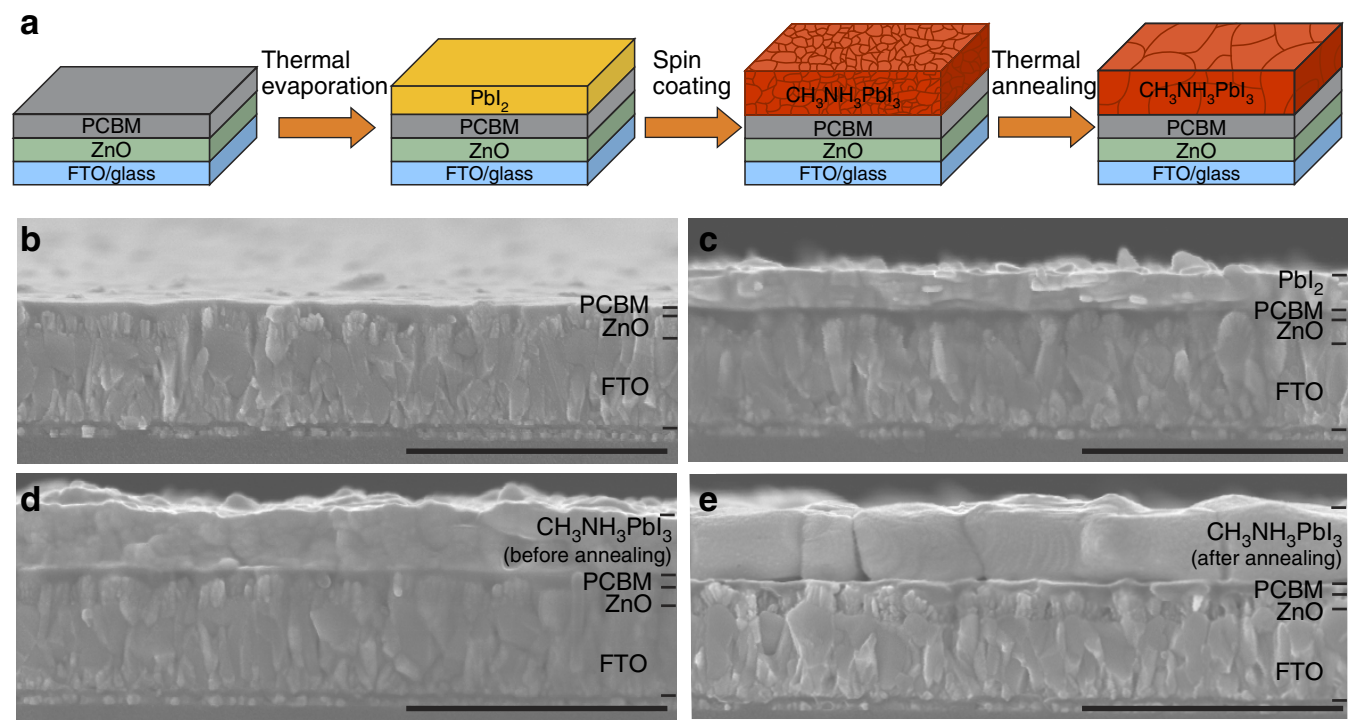

Figure 1 | Hybrid thermal evaporation-spin coating preparation method and corresponding microstructure. (a) Deposition of perovskite layer through a combined thermal evaporation of $\mathrm{Pbl}_{2}$ and spin coating of $\mathrm{CH}_{3} \mathrm{NH}_{3}$ l solution in isopropanol followed by $2 \mathrm{~h}$ annealing at $50{ }^{\circ} \mathrm{C}$ on hotplate. (b-e) The cross-sectional SEM images of each layer during perovskite preparation. Scale bars, $1 \mu \mathrm{m}$ in $\mathbf{b}-\mathbf{e}$. 
transmittance between 800 and $1,150 \mathrm{~nm}$. Such a device when operated as a bifacial cell yields an additional $13.5 \%$ power output improvement, and $20.5 \%$ efficiency is demonstrated using perovskite top cell and CIGS bottom cell in four-terminal tandem configuration.

\section{Results}

Low-temperature-processed planar perovskite solar cells. Figure 1 shows a schematic drawing and cross-sectional scanning electron microscopy (SEM) images of the perovskite absorber deposited by hybrid thermal evaporation-spin coating method. The high-temperature-processed $\mathrm{TiO}_{2}$ is replaced by $\sim 100 \mathrm{~nm}$ compact $\mathrm{ZnO}$ layer deposited through radio-frequency magnetron sputtering at room temperature, followed by spin coating of $\sim 50 \mathrm{~nm}$ PCBM. The room-temperature-processed ETL is attractive for low-cost, lightweight and flexible plastic substrates, and compatible with monolithic tandem fabrication. As illustrated in Fig. 1a, the perovskite layer is formed through a hybrid evaporation solution approach, where a compact $\mathrm{PbI}_{2}$ layer is initially deposited by thermal evaporation ${ }^{37}$. This method allows a uniform and compact $\mathrm{PbI}_{2}$ deposited over large area. Then $\mathrm{CH}_{3} \mathrm{NH}_{3} \mathrm{I}$ in isopropanol solution is added by spin coating, followed by thermal annealing at $50^{\circ} \mathrm{C}$ for $2 \mathrm{~h}$ on hotplate. Afterwards, $\sim 200 \mathrm{~nm}$ Spiro-OMeTAD is spin coated on top of the perovskite. Finally, the cell is finished by evaporating $60 \mathrm{~nm} \mathrm{Au}$ for opaque reference solar cells. For semi-transparent solar cells, thermally evaporated $\mathrm{MoO}_{3}$ and room-temperaturesputtered $\mathrm{In}_{2} \mathrm{O}_{3}: \mathrm{H}$ are employed as rear contact. Thus, the highest processing temperature during the opaque and semi-transparent device fabrication is not higher than $50^{\circ} \mathrm{C}$. More detailed fabrication process information can be found in the Methods section.

For planar perovskite solar cells, a uniform and compact perovskite layer is essential for achieving high efficiency ${ }^{38}$. As $\mathrm{ZnO}$ conformally covers the rough fluorine-doped tin oxide (FTO) surface, the deposition of PCBM smoothens the surface where the perovskite is grown (Fig. 1b). Consequently, the
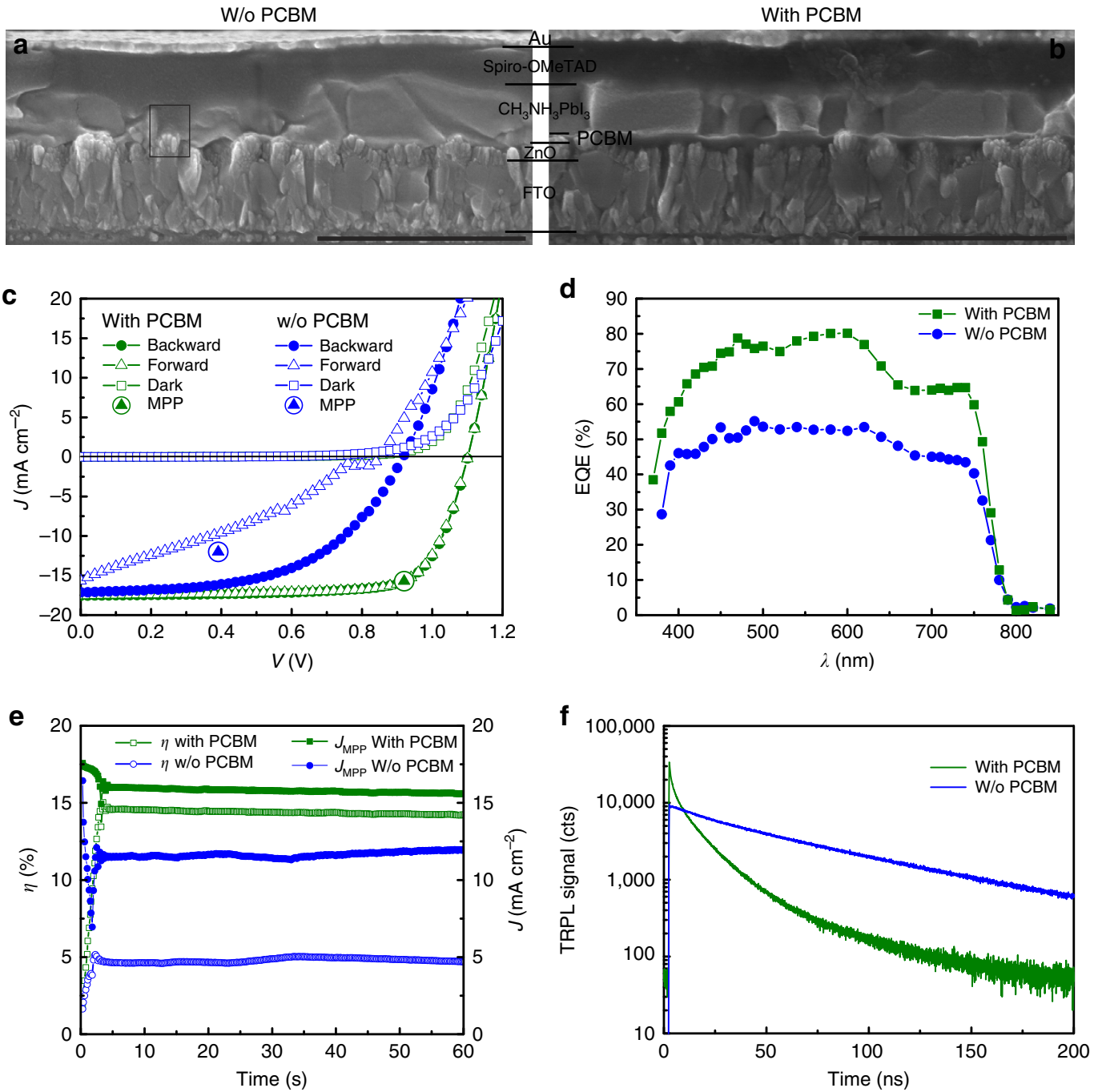

Figure 2 | Microstructure, time-resolved photoluminescence and photovoltaic performance of planar perovskite solar cells. (a,b) The cross-sectional SEM images of devices without (a) and with (b) PCBM, respectively. The rectangular area in a indicates shunting path. (c-e) The current density-voltage $(J-V)$ curves $(\mathbf{c})$, EQE spectra $(\mathbf{d})$ and steady-state efficiency at maximum power point $(\mathbf{e})$ of the planar perovskite solar cells. All the devices are measured under simulated AM1.5G irradiation with $1,000 \mathrm{Wm}^{-2}$ intensity. The $J-V$ measurements are performed in both forward $(-0.1$ to $1.2 \mathrm{~V})$ and backward $(1.2$ to $-0.1 \mathrm{~V})$ direction at a scan rate and delay time of $0.3 \mathrm{Vs}^{-1}$ and $10 \mathrm{~ms}$, respectively. The steady-state efficiency is evaluated by using a maximum power point tracker algorithm with constant AM1.5G illumination. (f) Time-resolved photoluminescence for samples with and without PCBM layer.

Scale bars, $1 \mu \mathrm{m}$ in $\mathbf{a}$ and $\mathbf{b}$. W/o, without. 
thermally evaporated $\mathrm{PbI}_{2}$ exhibits a compact and uniform layer over large area (Fig. 1c). Figure 1d,e presents the cross-sectional SEM images of perovskite layer before and after annealing, showing that the perovskite layer retained the desired compact morphology from parent $\mathrm{PbI}_{2}$. With thermal annealing, the grain size increases considerably from several tens of nanometres to values comparable to the film thickness (Fig. 1d,e), which might be beneficial to the transport and recombination properties of the absorber.

The herein introduced perovskite preparation method offers several merits. In previously reported two-step methods where $\mathrm{PbI}_{2}$ is spin coated from solution, it is quite challenging to control the morphology of the $\mathrm{PbI}_{2}$ film deposited from solution on planar substrates ${ }^{39}$. The low solubility of $\mathrm{PbI}_{2}$ in the commonly used solvent $\mathrm{N}, \mathrm{N}$-dimethylformide ${ }^{40}$ could limit the thickness variation and the choice of the underlying substrates where $\mathrm{PbI}_{2}$ is deposited. We overcome these challenges by using a simple thermal evaporation method, which can deposit a compact and uniform $\mathrm{PbI}_{2}$ layer with precisely controlled thickness over large area. The room-temperature vapour deposition has no constraints on the underlying substrates, which opens up numerous possibilities for exploring other solvent-sensitive carrier-selective contacts and novel cell structure. For instance, this process allows the introduction of PCBM below the perovskite layer, which is crucial to eliminate the $J-V$ hysteresis $^{24}$, but difficult to realize in solution process as the commonly used polar solvents, such as $N, N$-dimethylformide, dimethylsulfoxide or $\gamma$-butyrolactone, for perovskite formation are detrimental to thin layers of PCBM.

Planar perovskite solar cells without $J-V$ hysteresis. The hybrid thermal evaporation-spin coating method enables us to investigate the influences of PCBM on perovskite microstructure and device performance in regular planar configuration. Figure $2 a, b$ presents the cross-sectional SEM images of the planar perovskite solar cell with and without PCBM layer, respectively. Other than PCBM, the devices are fabricated by an identical process with perovskite layer grown from $120 \mathrm{~nm} \mathrm{PbI}_{2}$ (estimated by quartz microbalance) and $40 \mathrm{mg} \mathrm{ml}^{-1} \mathrm{CH}_{3} \mathrm{NH}_{3} \mathrm{I}$ solution. It can be seen from the SEM images that the perovskite layer shows considerable surface roughness and thickness non-uniformity when grown directly on $\mathrm{ZnO}$, which leads to low-resistance shunting paths and insufficient light absorption. A uniform and compact perovskite layer with large grain size is obtained when grown on PCBM. The microstructural difference in perovskite layers is mainly attributed to the morphological differences in $\mathrm{PbI}_{2}$ layers, as shown in Supplementary Fig. 1. If $\mathrm{PbI}_{2}$ is grown on $\mathrm{ZnO}$ directly, porous layers comprising numerous nanoplates are obtained $^{41}$. This could form lots of grain boundaries and defects after the conversion into perovskite. It is important to note that high-efficiency devices produced by the here described process always contain residual $\mathrm{PbI}_{2}$ as shown in Supplementary Fig. 2. The existence of residual $\mathrm{PbI}_{2}$ is also observed in many highefficiency devices reported in literature and several beneficial effects, for example, grain boundary passivation, hole-blocking effect and so on, have been proposed ${ }^{42,43}$.

Figure $2 c$ shows the $J-V$ characteristics of the corresponding planar perovskite solar cells under simulated AM1.5G irradiation. Owing to the hysteresis in $J-V$ measurements ${ }^{31}$, it is crucial to report both forward (short circuit to forward bias) and backward (forward bias to short circuit) measurements along with the measurement conditions. The photovoltaic parameters are summarized in Supplementary Table 1. The device with PCBM layer shows an open circuit voltage $\left(V_{\text {oc }}\right)$ of $1.101 \mathrm{~V}$, short circuit current density $\left(J_{\mathrm{sc}}\right)$ of $17.6 \mathrm{~mA} \mathrm{~cm}^{-2}$ and fill factor (FF) of
$74.9 \%$, resulting in power conversion efficiency $(\eta)$ of $14.5 \%$ in forward scan. In backward scan a $V_{\text {oc }}$ of $1.103 \mathrm{~V}, J_{\mathrm{sc}}$ of $17.5 \mathrm{~mA} \mathrm{~cm}^{-2}$, FF of $74.6 \%$ and $\eta$ of $14.4 \%$ are obtained. The $J-V$ curves from forward and backward scans coincide well, indicating no $J-V$ hysteresis is observed in the devices. The $J_{\mathrm{sc}}$ is confirmed by external quantum efficiency (EQE) measurement (Fig. 2d) with an integrated $J_{\mathrm{sc}}$ of $17.4 \mathrm{~mA} \mathrm{~cm}^{-2}$ under AM1.5G spectrum. Furthermore, the efficiency measured at the maximum power point (MPP), that is, the steady-state output of the device, is shown in Fig. 2e. The cell exhibits a steady-state efficiency of $14.4 \%$ and current density of $15.7 \mathrm{~mA} \mathrm{~cm}^{-2}$ at MPP under continuous illumination. This is consistent with the $J-V$ and $\mathrm{EQE}$ measurements. The device without PCBM layer generally shows a lower $V_{\mathrm{oc}}, J_{\mathrm{sc}}$ and FF with pronounced $J-V$ hysteresis, and the steady-state efficiency lies between forward and backward efficiency. The integrated $J_{\mathrm{sc}}$ of $12.1 \mathrm{mAcm}^{-2}$ is also lower than that derived from the $J-V$ measurement.

Time-resolved photoluminescence decays are presented in Fig. $2 f$ to probe the effect of PCBM on carrier dynamics in perovskite solar cells. In both cases the decay tails allow to estimate a minority carrier lifetime of $\sim 80 \mathrm{~ns}$ (ref. 44). Furthermore, it can be seen that the addition of PCBM leads to a nonlinear initial PL transient, which can be explained by charge-separating fields ${ }^{45}$. This indicates that the application of PCBM promotes a working junction without the need of initial biasing. Therefore, the elimination of $J-V$ hysteresis and enhanced photovoltaic performance primarily stem from improved interface and junction formation and from the highquality perovskite layer with enhanced crystallinity, uniform and compact morphology with large grain size.

Semi-transparent planar perovskite solar cells. For semitransparent cells, the opaque $\mathrm{Au}$ is substituted by $\operatorname{In}_{2} \mathrm{O}_{3}: \mathrm{H}$ transparent electrodes. $\operatorname{In}_{2} \mathrm{O}_{3}: \mathrm{H}$ is a high-mobility TCO material with superior visible and NIR transmittance ${ }^{46}$, and excellent thermal and chemical stability for solar cell applications were reported ${ }^{47}$. Deposition of $\mathrm{In}_{2} \mathrm{O}_{3}: \mathrm{H}$ by sputtering at room temperature without post-annealing results in layers with reasonably high mobility of $51.3 \mathrm{~cm}^{2} \mathrm{~V}^{-1} \mathrm{~s}^{-1}$ and sheet resistance of $25.7 \Omega$ per square for $149 \mathrm{~nm}$ thick (determined from profilometer) amorphous layers. The effect of postannealing treatment on the electrical properties (sheet resistance, electron mobility and electron density) and optical properties (transmission and absorption) of $\operatorname{In}_{2} \mathrm{O}_{3}: \mathrm{H}$ films on glass is presented in Supplementary Fig. 3. The amorphous nature of the as-sputtered $\operatorname{In}_{2} \mathrm{O}_{3}: \mathrm{H}$ is confirmed by X-ray diffraction (Supplementary Fig. 4). The radio-frequency sputtering method is a high-throughput and industrial scale method. However, high energetic ion bombardment during sputtering can damage the underlying layers. This is especially the case for organic layers such as Spiro-OMeTAD. Two different TCOs, that is, $\mathrm{ZnO}: \mathrm{Al}$ and $\mathrm{In}_{2} \mathrm{O}_{3}: \mathrm{H}$, are deposited by radio-frequency magnetron sputtering with different extent of ion bombardment and compared as transparent electrode.

The degree of ion bombardment is more severe during the deposition of $\mathrm{ZnO}: \mathrm{Al}$ than that in $\mathrm{In}_{2} \mathrm{O}_{3}: \mathrm{H}$ due to the different sputter geometries, lower total pressure and shorter target-tosubstrate distance ${ }^{48}$, as illustrated in Supplementary Fig. 5. In both devices, $8.7 \mathrm{~nm} \mathrm{MoO}_{3}$ is evaporated as buffer layer, and perovskite is grown from $120 \mathrm{~nm}$-thick $\mathrm{PbI}_{2}$ precursor. As can be seen in Fig. 3a,d, the average $V_{\mathrm{oc}}, J_{\mathrm{sc}}, \mathrm{FF}$ and $\eta$ of devices with $\mathrm{ZnO}: \mathrm{Al}$ are much lower than that of the ones with $\operatorname{In}_{2} \mathrm{O}_{3}: \mathrm{H}$, and the s.d. is also larger in case of $\mathrm{ZnO}$ :Al. Notably, a perovskite solar cell with $10.1 \%$ efficiency (Supplementary Fig. 6) is achieved by directly depositing $\operatorname{In}_{2} \mathrm{O}_{3}: \mathrm{H}$ on top of Spiro-OMeTAD. This is the 

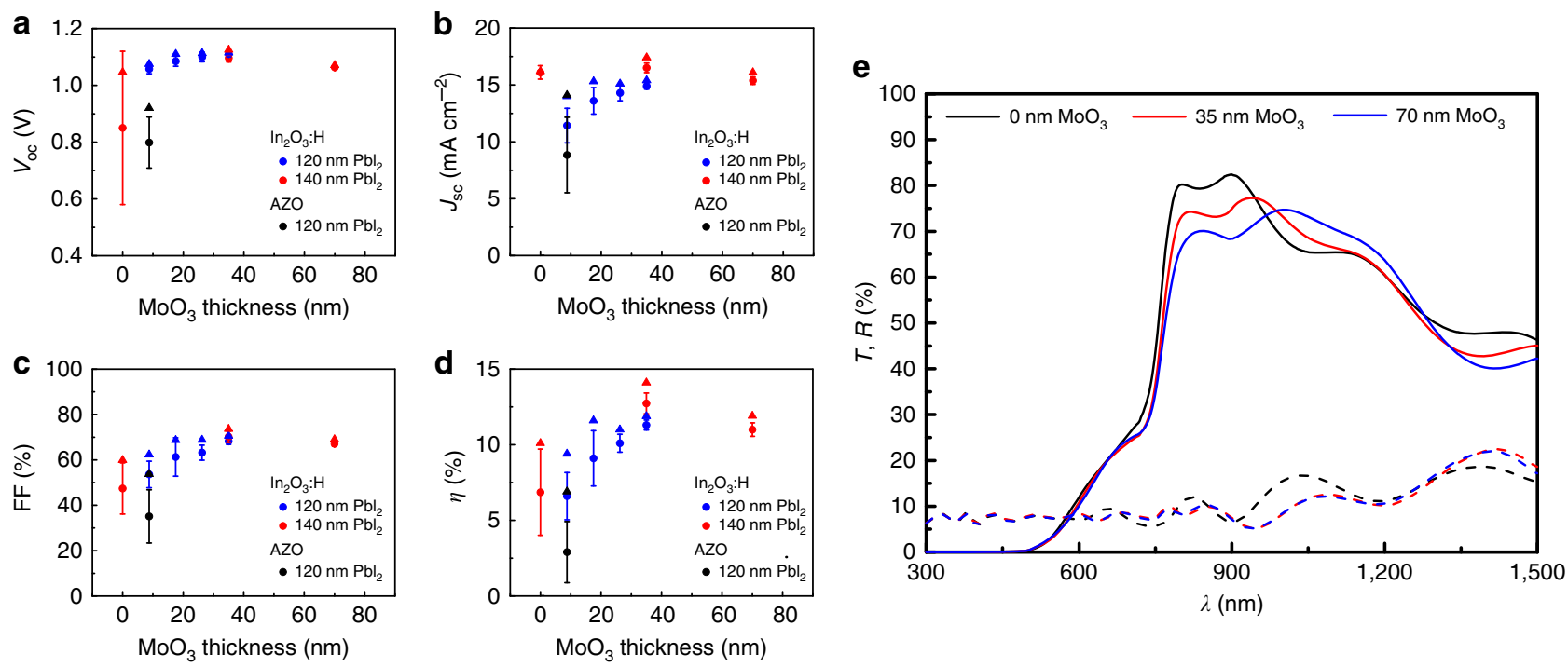

Figure 3 | Photovoltaic and optical properties of semi-transparent planar perovskite solar cells with different $\mathbf{M o O}_{\mathbf{3}}$ thickness. (a-d) The photovoltaic parameters of semi-transparent planar solar cells as a function of $\mathrm{MoO}_{3}$ thickness with $\ln _{2} \mathrm{O}_{3}: \mathrm{H}$ as rear transparent electrode. The photovoltaic performances of device with $\mathrm{ZnO}: \mathrm{Al}$ rear contact are also presented for comparison. Average values and s.d. are given from 5 to $9 \mathrm{cells}$ (cell area: $0.3 \mathrm{~cm}{ }^{2}$ for $\mathrm{In}_{2} \mathrm{O}_{3}: \mathrm{H}$; and $0.15 \mathrm{~cm}^{2}$ for $\mathrm{ZnO}: \mathrm{Al}$ ). The triangle symbol represents the highest value for each batch. The $J-V$ measurement conditions were the same as in Fig. 2. (e) The transmission $(T)$ and reflection $(R)$ of semi-transparent cells with various $\mathrm{MoO}_{3}$ thicknesses. The solid and dashed lines represent transmission and reflection, respectively. The perovskite is grown from $140 \mathrm{~nm} \mathrm{Pbl}_{2}$ precursor. The $\mathrm{MoO}_{3}$ thickness used here is determined from $\mathrm{SEM}$ images.

highest value with direct deposition of TCO on top of the hole transporting layer (HTL) as back electrode without buffer layer, indicating that direct sputtered TCO might allow to achieve highefficiency if the ion bombardment is suppressed during deposition.

In the current device architecture and deposition procedure, the use of $\mathrm{MoO}_{3}$ proves still to be beneficial. Figure 3 shows the photovoltaic and optical properties as a function of the $\mathrm{MoO}_{3}$ thickness as well as the schematic cell structure of semitransparent planar perovskite solar cell. A general increase of all the photovoltaic parameters combined with a substantial increase in uniformity is observed with increasing $\mathrm{MoO}_{3}$ thickness up to $35 \mathrm{~nm}$. Further, it is shown that the $J_{\mathrm{sc}}$ is less sensitive to $\mathrm{MoO}_{3}$ thickness variation if the $\mathrm{PbI}_{2}$ precursor thickness is increased to $140 \mathrm{~nm}$ while the $\mathrm{FF}$ and $V_{\mathrm{oc}}$ exhibit the same trend as devices grown from $120 \mathrm{~nm} \mathrm{PbI}_{2}$ precursors. For $\mathrm{MoO}_{3}$ thicknesses above $35 \mathrm{~nm}$ no increase is observed anymore. The highest $V_{\mathrm{oc}}$ and $\mathrm{FF}$ in semi-transparent cells are comparable to opaque reference ones, indicating a reasonable trade-off between minimized sputtering damage and added series resistance with $35 \mathrm{~nm} \mathrm{MoO}_{3}$ thickness. In addition to the photovoltaic performance, the $\mathrm{MoO}_{3}$ thickness also affects the transmission and reflection spectra as shown in Fig. 3e. The transmission shows a decreasing trend with increasing $\mathrm{MoO}_{3}$ thickness between 800 and $940 \mathrm{~nm}$, while an opposite trend with thickness variation between 940 and $1,200 \mathrm{~nm}$. The device without $\mathrm{MoO}_{3}$ shows a peak transmission of $82 \%$, while device with $35 \mathrm{~nm}$ $\mathrm{MoO}_{3}$ shows the highest average transmission in $800-1,150 \mathrm{~nm}$ region. Therefore, an optimal $35 \mathrm{~nm}$-thick $\mathrm{MoO}_{3}$ layer is deposit on Spiro-OMeTAD before $\mathrm{In}_{2} \mathrm{O}_{3}: \mathrm{H}$ deposition in terms of photovoltaic and optical properties in the following work.

Figure 4 summarizes the microstructure, transmission and photovoltaic performance of a semi-transparent planar perovskite solar cell produced as described above. The cross-sectional SEM image in Fig. 4a shows a cell structure of $\mathrm{FTO} / \mathrm{ZnO} / \mathrm{PCBM} /$ $\mathrm{CH}_{3} \mathrm{NH}_{3} \mathrm{PbI}_{3} /$ Spiro-OMeTAD/ $\mathrm{MoO}_{3} / \mathrm{In}_{2} \mathrm{O}_{3}: \mathrm{H}$. An electron beam-evaporated $\mathrm{Ni}$-Al grid is applied for better charge carrier collection in cells with area above $0.5 \mathrm{~cm}^{2}$. The cell area is defined by mechanical scribing down to the FTO layer. The perovskite grown from $140 \mathrm{~nm} \mathrm{PbI}_{2}$ and $45 \mathrm{mg} \mathrm{ml}^{-1} \mathrm{CH}_{3} \mathrm{NH}_{3} \mathrm{I}$ solution shows a flat and dense layer with grain size comparable to the film thickness. Figure $4 \mathrm{~b}$ displays the transmission, reflection and absorption of the semi-transparent cell. The transmission through the whole device shows a peak of $77 \%$ at $940 \mathrm{~nm}$ and an average of $72 \%$ between 800 and $1,150 \mathrm{~nm}$. The high sub-bandgap transmission is attributed to the low free-carrier absorption in high-mobility $\mathrm{In}_{2} \mathrm{O}_{3}: \mathrm{H}$ (ref. 48). In addition, the photograph of the semi-transparent device in the inset of Fig. $4 \mathrm{~b}$ shows a decent transmission in visible region as the picture behind the device can be clearly recognized. The hatched area in Fig. $4 \mathrm{~b}$ indicates optical losses due to insufficient absorption in the perovskite layer. This means there is still much room to increase the current in the semi-transparent cell by optimizing the (optical) thickness of perovskite layer.

Figure $4 c, d$ presents the $J-V$ curves and EQE spectra of the semi-transparent planar perovskite solar cell illuminated from front (FTO) and rear $\left(\operatorname{In}_{2} \mathrm{O}_{3}: \mathrm{H}\right)$ side. The forward and backward scans show negligible $J-V$ hysteresis. The corresponding photovoltaic parameters are summarized in Supplementary Table 1. The semi-transparent device shows a $V_{\mathrm{oc}}$ of $1.104 \mathrm{~V}, J_{\mathrm{sc}}$ of $17.4 \mathrm{~mA} \mathrm{~cm}^{-2}$, FF of $73.6 \%$ and $\eta$ of $14.1 \%$ illuminated from FTO, and $V_{\mathrm{oc}}$ of $1.105 \mathrm{~V}, J_{\mathrm{sc}}$ of $12.2 \mathrm{~mA} \mathrm{~cm}^{-2}, \mathrm{FF}$ of $70.6 \%$ and $\eta$ of $9.5 \%$ illuminated from $\operatorname{In}_{2} \mathrm{O}_{3}: \mathrm{H}$, as shown in Fig. 4 c. The $V_{\mathrm{oc}}$ remains the same regardless of the illumination side, while higher $J_{\text {sc }}$ and FF are observed when illuminated from FTO side. The EQE spectra are consistent with the $J_{\text {sc }}$ discrepancy in $J-V$ curves, where rear illumination shows a lower EQE, particularly below $430 \mathrm{~nm}$. This distinct difference can be well explained by the strong parasitic absorption of Spiro-OMeTAD (Supplementary Fig. 7). Strong interference and the shading effect of metal grid also contribute to the lower current density when illuminated from rear side. The semi-transparent cell shows a high $V_{\text {oc }}$ of $1.1 \mathrm{~V}$, comparable to the reference cell. The FF is slightly reduced due to the lower conductivity of the $\mathrm{In}_{2} \mathrm{O}_{3}: \mathrm{H} / \mathrm{Ni}$-Al grid contact 
a

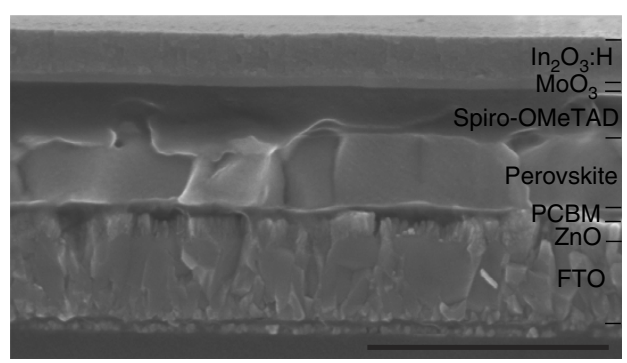

C

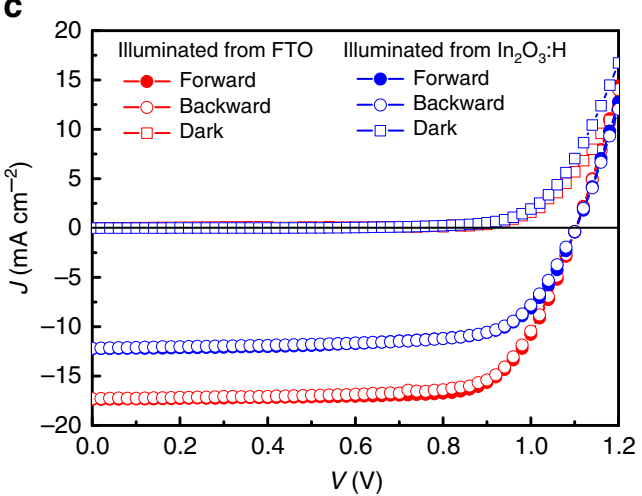

e

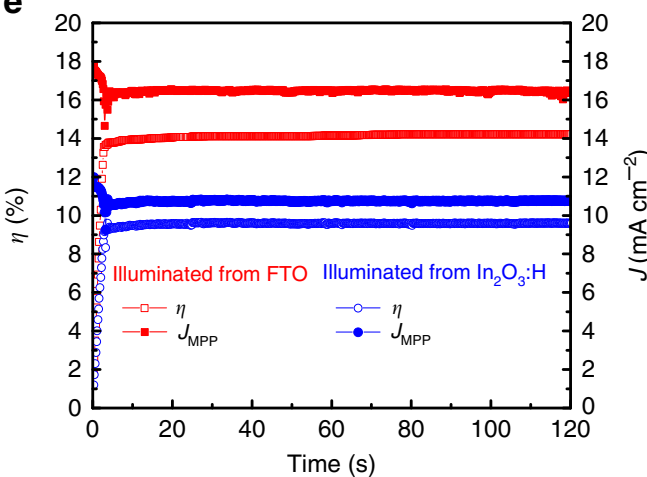

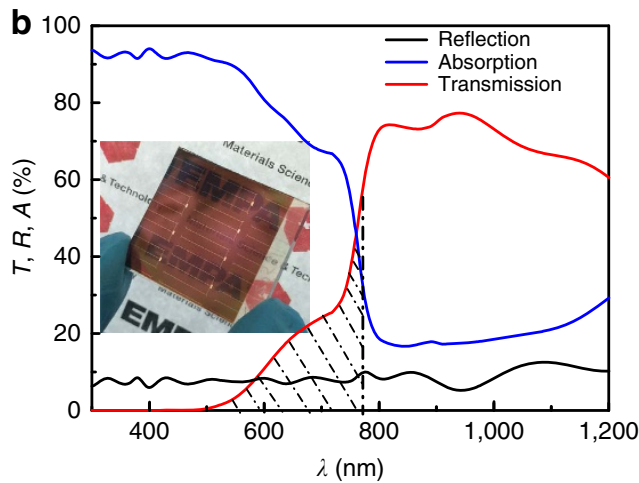

d

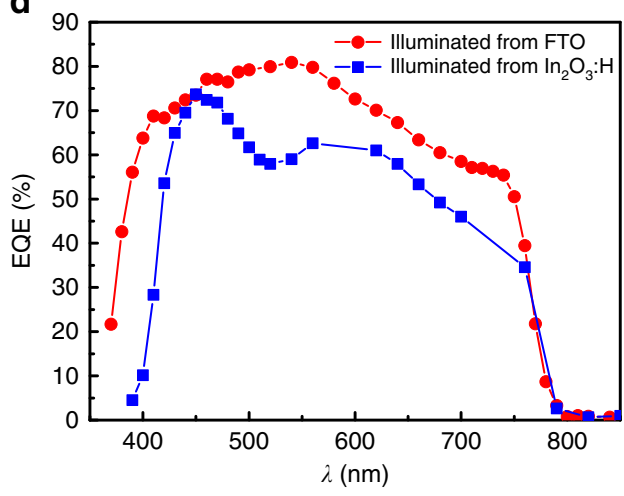

f

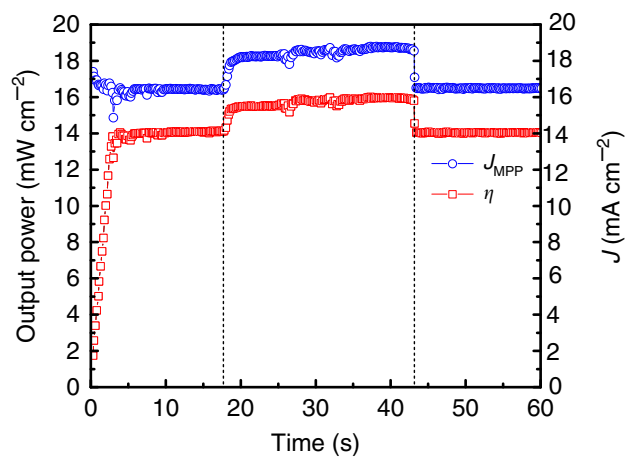

Figure 4 | Microstructure and photovoltaic performance of the semi-transparent planar perovskite solar cell. (a) The cross-sectional SEM image of the complete device. Scale bar, $1 \mu \mathrm{m}$. (b) The transmission $(T)$, reflection $(R)$ and absorption $(A)$ of semi-transparent cell. A photograph of the semi-transparent device is also shown as inset. Current density-voltage $(J-V)$ curve (c), external quantum efficiency (EQE) spectra (d) and steady-state efficiency at maximum power point (e) of the semi-transparent planar perovskite solar cell. (f) Bifacial application of the semi-transparent cell with white paper as reflective background. The first and second dashed lines indicate the insertion and removal of the commercial white paper as reflective background, respectively. The measurement conditions in the J-V, EQE and MPP are same as in Fig. 2.

compared with Au. Generally, the current density in the semitransparent cell is lower than that in the opaque cell when the perovskite layer is grown from same $\mathrm{PbI}_{2}$ thickness $(120 \mathrm{~nm})$ as shown in Supplementary Fig. 8. To verify the efficiency measured from $J-V$, the steady-state output at MPP is measured and presented in Fig. 4e. On illumination, the current density and efficiency increase within $3 \mathrm{~s}$ (ramp up of the MPP tracker) to $16.4 \mathrm{~mA} \mathrm{~cm}^{-2}$ and $14.2 \%$ for front illumination, and $10.8 \mathrm{~mA} \mathrm{~cm}^{-2}$ and $9.6 \%$ for rear illumination, respectively. The steady-state power conversion efficiency of $14.2 \%$ is the highest reported value for semi-transparent planar perovskite solar cell to date, which is particularly remarkable due to the simultaneously high transparency in NIR region. In addition, the semitransparent cell with $\operatorname{In}_{2} \mathrm{O}_{3}: \mathrm{H}$ showed improved air stability compared with the opaque cell with $\mathrm{Au}$ in a preliminary stability experiment, as shown in Supplementary Fig. 9. In the following, two of many applications of high-efficiency semi-transparent perovskite solar cells are discussed in more detail.

Bifacial planar perovskite solar cell. Bifacial solar cells are capable of converting sunlight incident from the front and the rear side of the cell into electricity, therefore the power output could be improved if highly reflective surrounding is present behind rear side of the cell. To illustrate how the power output gain works, we simply put a white paper from a commercial notebook as reflective surrounding under rear side of the cell during the MPP measurement. As shown in Fig. 4f, the power output quickly increased from original 14.1 to $16.0 \mathrm{~mW} \mathrm{~cm}^{-2}$ after adding the white paper behind the solar cell, while it

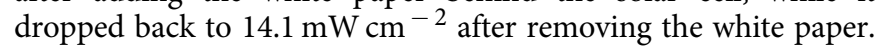
Using white paper as reflective surrounding gives $13.5 \%$ 

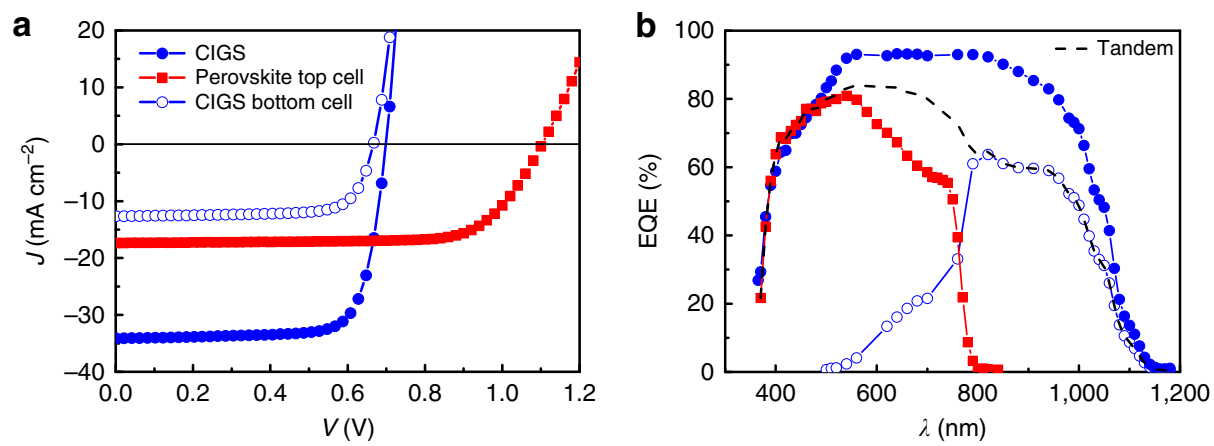

Figure 5 | Photovoltaic performance of the four-terminal perovskite-CIGS tandem solar cell. (a,b) The current density-voltage (J-V) curves (a) and EQE spectra (b) of the four-terminal tandem device.

Table 1 | Photovoltaic parameters of the four-terminal perovskite-CIGS tandem solar cells.

\begin{tabular}{|c|c|c|c|c|c|c|}
\hline Solar cells & $V_{\mathrm{OC}}(\mathrm{mV})$ & $J_{S C}\left(m_{A c m}^{-2}\right)$ & Calculated $\mathrm{J}_{\mathrm{SC}}\left(\mathrm{mA} \mathrm{cm}{ }^{-2}\right)$ & FF (\%) & $\eta(\%)$ & Steady-state efficiency (\%) \\
\hline Perovskite top subcell & 1,104 & 17.4 & 16.7 & 73.6 & 14.1 & 14.2 \\
\hline CIGS bottom subcell & 667.4 & 12.7 & 12.4 & 74.9 & 6.3 & 6.3 \\
\hline
\end{tabular}

performance enhancement. By using a more reflective background and proper arrangement of solar modules in a system, the output power gain can be further improved up to $50 \%$ as demonstrated in silicon technology by Ceuvas et al. ${ }^{13}$.

Four-terminal perovskite-CIGS tandem solar cell. A fourterminal mechanically stacked tandem device is demonstrated based on perovskite as top subcell and CIGS as bottom subcell, as schematically shown in Supplementary Fig. 10. The CIGS absorber layer is fabricated by a multistage co-evaporation process $^{49}$. In a four-terminal tandem device, the top and bottom subcells are individually processed and mechanically stacked together. As the top cell and bottom subcell are electrically independent, two MPP trackers can be used to ensure optimum operation of each subcell at any condition. This also means that the efficiency of each subcell can be evaluated separately, and the sum of the two gives the efficiency of the device in tandem configuration. In this work, the performance of the bottom CIGS is directly measured with perovskite as a filter under standard illumination (Supplementary Fig. 10). The cell area of the bottom CIGS is defined by a laser-scribed shadow mask with aperture of $0.213 \mathrm{~cm}^{2}$ inserted between the top and bottom subcells.

The $J-V$ curves and EQE spectra of the top and bottom subcells are displayed in Fig. 5, and the photovoltaic parameters are summarized in Table 1. For comparison, the photovoltaic performance of the CIGS without perovskite filter is also presented. After adding the perovskite top cell as filter, the $J_{\mathrm{sc}}$ of the bottom CIGS decreased as expected due to reduced light intensity. The FF and $V_{\mathrm{oc}}$ are only marginally reduced, resulting in $6.3 \%$ efficiency for the CIGS bottom cell. Together with the $14.2 \%$ efficiency of the perovskite top, this result in $20.5 \%$ efficiency for the device in tandem configuration, which is a substantial improvement compared with each single-junction efficiency as well as to what was reported earlier for polycrystalline thin-film solar cells in tandem configuration ${ }^{32-35,50-52}$.

Currently, the transmission is still limited by the strong parasitic absorption in the front FTO electrode. The lowtemperature process presented here facilitates the use of more transparent TCOs, such as $\operatorname{In}_{2} \mathrm{O}_{3}: \mathrm{H}$ or indium zinc oxide. The transmission and absorption spectra of $\operatorname{In}_{2} \mathrm{O}_{3}: \mathrm{H}, \mathrm{ZnO}: \mathrm{Al}$ and commercially available FTO and ITO are compared in Supplementary Fig. 11. The $\operatorname{In}_{2} \mathrm{O}_{3}: \mathrm{H}$ has the lowest absorption among all the TCOs investigated here between 300 and 2,000 nm. This implies there is much room in further lowering the parasitic absorption of semi-transparent perovskite solar cell in NIR region if front FTO is replaced by high-mobility $\operatorname{In}_{2} \mathrm{O}_{3}: \mathrm{H}$. Since both the fabrication process for the CIGS solar cell and the for the perovskite cell are compatible to deposition on polymer films, lightweight and bendable polycrystalline tandem devices are in reach. Optimization of the bandgap of top and bottom cells, application of anti-reflection coating and optical coupling media can lead to even higher tandem efficiency in the near future as discussed in more detail by Kranz et al. ${ }^{33}$.

\section{Discussion}

In conclusion, a low-temperature-processed high-efficiency semitransparent planar perovskite solar cell without $J-V$ hysteresis is developed by using sputtered hydrogenated indium oxide $\left(\mathrm{In}_{2} \mathrm{O}_{3}: \mathrm{H}\right)$ as transparent rear electrode. The high-temperatureprocessed $\left(\sim 500^{\circ} \mathrm{C}\right) \mathrm{TiO}_{2}$ is replaced by room-temperaturesputtered $\mathrm{ZnO}$, and the perovskite is prepared by a combined thermal evaporation of $\mathrm{PbI}_{2}$ and spin coating of $\mathrm{CH}_{3} \mathrm{NH}_{3} \mathrm{I}$ followed by 2 - $\mathrm{h}$ annealing at $50{ }^{\circ} \mathrm{C}$, thus making the maximum processing temperature as low as $50^{\circ} \mathrm{C}$. The hybrid thermal evaporation-spin coating method enables the introduction of PCBM in regular device configuration, which results in a highquality perovskite layer and better electron collection, thus leads to a $14.5 \%$ hysteresis-free planar perovskite solar cell. Highmobility $\mathrm{In}_{2} \mathrm{O}_{3}: \mathrm{H}$ is employed as transparent rear electrode deposited by sputtering at room temperature, which enables a semi-transparent planar perovskite solar cell with high steadystate efficiency of $14.2 \%$ and simultaneous $72 \%$ average transmission between 800 and $1,150 \mathrm{~nm}$. Finally, we show a $13.5 \%$ output power enhancement when the semi-transparent cell functioned as bifacial solar cell and demonstrate $20.5 \%$ efficiency device with perovskite top cell and CIGS bottom cell in fourterminal tandem configuration. This work has significant beneficial implications in lightweight tandem solar cells, bifacial 
solar cell, photon energy upconversion, photovoltaic-integrated buildings and wearable/portable electronics.

\section{Methods}

Perovskite solar cell fabrication. Perovskite solar cells were grown on FTO-coated glass (Pilkington, $15 \Omega$ per square.) substrates. The $5 \mathrm{~cm} \times 5 \mathrm{~cm}$ FTO/glasses were washed by hand followed by ultrasonic soap and water baths, and then cut into four quarters. Subsequently, a $100 \mathrm{~nm}$ compact $\mathrm{ZnO}$ layer was deposited at room temperature by radio-frequency magnetron sputtering on top of the $\mathrm{FTO} /$ glass at a deposition pressure of $6 \times 10^{-3}$ mbar with $\mathrm{Ar}$ and $\mathrm{O}_{2}$ flow of 45 and $16 \mathrm{sccm}$, respectively. The deposition power density was $1.9 \mathrm{~W} \mathrm{~cm}^{-2}$, and the deposition time was $4.5 \mathrm{~min}$. Then $30 \mu \mathrm{l}$ of PCBM solution $\left(20 \mathrm{mg} \mathrm{ml}^{-1}\right.$ in chlorobenzene) was spin coated on top of $\mathrm{ZnO}$ at 2,000 r.p.m. for $40 \mathrm{~s}$ in the glovebox. The $\mathrm{PbI}_{2}$ film was thermally evaporated on rotating $\mathrm{PCBM} / \mathrm{ZnO} / \mathrm{FTO} /$ glass substrates at a deposition pressure of $2-5 \times 10^{-8} \mathrm{mbar}$. Unless otherwise noted, the deposition rate is controlled within $1.2-1.6 \AA \mathrm{s}^{-1}$, monitored by a quartz crystal microbalance. The thicknesses of $\mathrm{PbI}_{2}$ precursors for opaque cells is $120 \mathrm{~nm}$. For semi-transparent devices, 120 and $140 \mathrm{~nm}$ were used. After the $\mathrm{PbI}_{2}$ deposition, the samples were subsequently transferred into a $\mathrm{N}_{2}$-filled glovebox for further processing. The perovskite layer was formed by spin coating of $\mathrm{CH}_{3} \mathrm{NH}_{3} \mathrm{I}$ (Dyesol, 99.9\%) in 2-propanol at a concentration of 40 and $45 \mathrm{mg} \mathrm{ml}^{-1}$ for 120 and $140 \mathrm{~nm} \mathrm{PbI}_{2}$, respectively. The solution was first spread to cover the whole substrate, and the rotation (2,000 r.p.m. for $40 \mathrm{~s}$ ) was started after $10 \mathrm{~s}$. The as-prepared films were annealed at $50^{\circ} \mathrm{C}$ for $2 \mathrm{~h}$ on a hotplate inside the glovebox. After annealing, the samples were cooled down to room temperature and $30 \mu \mathrm{l}$ of a Spiro-OMeTAD solution (72.3 mg 2,2',7,7'-tetrakis-( $N, N^{\prime}$-di- $p$ methoxyphenylamine)-9,9'-spirobifluorene (Spiro-OMeTAD; Merck), $17.5 \mu \mathrm{l}$ lithium-bis(trifluoromethanesulfonyl)imide (Li-TFSI, Sigma-Aldrich) solution (520 mg Li-TFSI in $1 \mathrm{ml}$ acetonitrile, Sigma-Aldrich) and $28.8 \mu \mathrm{l}$ 4-tertbutylpyridine (TBP, Sigma-Aldrich) all dissolved in 1,000 $\mu \mathrm{l}$ chlorobenzene (Sigma-Aldrich)) was spin coated on top of the perovskite at 2,000 r.p.m. for 40 s. The devices were finished by evaporating $60 \mathrm{~nm}$ Au through a metal mask under high vacuum $\left(<5 \times 10^{-6} \mathrm{mbar}\right)$, defining the cell area of $0.15 \mathrm{~cm}^{2}$ for reference cells. For semi-transparent devices, a $35 \mathrm{~nm}$ thick $\mathrm{MoO}_{3}$ was deposited on top of Spiro-OMeTAD via thermal evaporation, which was covered by $170 \mathrm{~nm}$ of $\mathrm{In}_{2} \mathrm{O}_{3}: \mathrm{H}$ as transparent electrode. Ni/Al/Ni grids with $50 \mathrm{~nm} / 2,000 \mathrm{~nm} / 50 \mathrm{~nm}$ thickness were deposited by electron beam evaporation. Finally, the cell area $\left(0.517 \mathrm{~cm}^{2}\right)$ is defined by mechanical scribing. No anti-reflection coating is applied for the semi-transparent cells.

Radio-frequency sputtering of hydrogenated indium oxide. Hydrogenated indium oxide $\left(\mathrm{In}_{2} \mathrm{O}_{3}: \mathrm{H}\right)$ layers were deposited in a high vacuum sputtering system (AJA Int.) by radio-frequency sputtering of ceramic $\mathrm{In}_{2} \mathrm{O}_{3}(99.99 \%)$ targets at an applied sputter power density of $3.0 \mathrm{~W} \mathrm{~cm}^{-2}$ without intentional heating of the substrate. The reactive atmosphere consisted of a gas mixture of $\mathrm{Ar}, \mathrm{O}_{2}$ and $\mathrm{H}_{2} \mathrm{O}$ at a total pressure of $0.6 \mathrm{~Pa} . \mathrm{H}_{2} \mathrm{O}$ vapour for $\mathrm{H}$ doping was injected via a needle valve with a partial pressure of $\sim 1 \times 10^{-4} \mathrm{~Pa}$.

Radio-frequency sputtering of aluminium doped zinc oxide. Aluminium-doped zinc oxide (ZnO:Al) layers were deposited in a high-vacuum sputtering system by radio-frequency sputtering of ceramic $\mathrm{ZnO}$ (containing $2 \mathrm{wt} \% \mathrm{Al}_{2} \mathrm{O}_{3}$ ) targets. The sputtering deposition consist of a 5 -min deposition ramp up from 0.6 to $2.5 \mathrm{~W} \mathrm{~cm}^{-2}$ and followed by $5 \times 3 \mathrm{~min}$ at $2.5 \mathrm{~W} \mathrm{~cm}^{-2}$ under $20 \mathrm{sccm} \mathrm{Ar}$ and $0.29 \mathrm{sccm} \mathrm{Ar} / \mathrm{O}_{2}\left(3 \mathrm{~mol} \% \mathrm{O}_{2}\right)$. There is a 30 -min waiting time during each step to alleviate the temperature effect.

X-ray diffraction measurements. X-ray diffraction patterns were obtained in Bragg-Brentano geometry by using a X'Pert PRO $\theta-2 \theta$ scan $\left(\mathrm{Cu}-\mathrm{K}_{\alpha 1}\right.$ radiation, $\lambda=1.5406 \AA$ ) from 10 to $60^{\circ}(2 \theta)$ with a step interval of $0.0167^{\circ}$.

Scanning electron microscopy. The cross-sectional images of the samples were investigated with a Hitachi S- 4800 using $5 \mathrm{kV}$ voltage and $10 \mathrm{~mA}$ current. A thin layer of Pt was coated on top of the sample to avoid charging effect.

Ultraviolet-visible spectroscopy. The transmission (T) and reflection (R) spectra were acquired using a ultraviolet-visible-NIR spectrophotometer (Shimadzu UV-3600) equipped with an integrating sphere. Absorption $A$ is calculated using the following formula: $A=1-T-R$.

Time-resolved photoluminescence. For time-resolved photoluminescence measurements, a $639 \mathrm{~nm}$ diode laser with pulse duration of $92 \mathrm{ps}$ was used as excitation source. Pulse repetition rates were around $1 \mathrm{MHz}$ and the number of photons per area and pulse was $\sim 1 \times 10^{13}$ photons per $\mathrm{cm}^{2}$. The spectrally integrated luminescence decay was measured using a Picoquant PMA-C 192-M photomultiplier time and a Picoquant TimeHarp 260 digitizing system with $50 \mathrm{ps}$ time channel width.
Hall effect measurements. Hall effect measurements of $\operatorname{In}_{2} \mathrm{O}_{3}: \mathrm{H}$ films were performed with a HMS 3,000 Hall effect measurement system at room temperature in the dark using van der Pauw geometry. The electron density and electron mobility were calculated from Hall measurements.

Solar cell performance characterization. The current density-voltage characteristics of perovskite solar cells were measured under standard simulated AM1.5G illumination using a Keithley 2,400 source meter. The illumination intensity was calibrated to $1,000 \mathrm{~W} \mathrm{~m}^{-2}$ using a certified single crystalline silicon solar cell. The $J-V$ measurement is performed in both forward (form $-0.1 \mathrm{~V}$ to $1.2 \mathrm{~V}$ ) and backward (from $1.2 \mathrm{~V}$ to $-0.1 \mathrm{~V}$ ) directions separately without any pretreatment (for example, light soaking, holding at forward bias for certain time and so on). The scan rate and delay time are $0.3 \mathrm{~V} \mathrm{~s}^{-1}$ and $10 \mathrm{~ms}$, respectively. The external quantum efficiency of the devices were measured with a lock-in amplifier. The probing beam was generated by a chopped white source $(900 \mathrm{~W}$, halogen lamp, $260 \mathrm{~Hz}$ ) and a dual grating monochromator. The beam size was adjusted to ensure that the illumination area was fully inside the cell area. A certified single crystalline silicon solar cell was used as the reference cell. White light bias was applied during the measurement with $\sim 0.1$ sun intensity. The steady-state efficiency as a function of time was recorded using a maximum power point tracker, which adjusts the applied voltage in order to reach the maximum power point (perturb and observe algorithm). The starting voltage is set to be $0.1 \mathrm{~V}$.

\section{References}

1. Snaith, H. J. Perovskites: the emergence of a new era for low-cost, high-efficiency solar cells. J. Phys. Chem. Lett. 4, 3623-3630 (2013).

2. Stranks, S. D. \& Snaith, H. J. Metal-halide perovskites for photovoltaic and light-emitting devices. Nat. Nanotechnol. 10, 391-402 (2015).

3. Yang, W. S. et al. High-performance photovoltaic perovskite layers fabricated through intramolecular exchange. Science 348, 1234-1237 (2015).

4. Beiley, Z. M. \& McGehee, M. D. Modeling low cost hybrid tandem photovoltaics with the potential for efficiencies exceeding 20\%. Energy Environ Sci. 5, 9173-9179 (2012).

5. Hübner, A., Aberle, A. G. \& Hezel, R. Novel cost-effective bifacial silicon solar cells with $19.4 \%$ front and $18.1 \%$ rear efficiency. Appl. Phys. Lett. 70, 1008-1010 (1997).

6. Cheng, Y. Y. et al. Improving the light-harvesting of amorphous silicon solar cells with photochemical upconversion. Energy Environ. Sci. 5, 6953-6959 (2012).

7. Hezel, R. Novel applications of bifacial solar cells. Prog. Photovolt. Res. Appl. 11, 549-556 (2003).

8. Zhou, C. Z. et al. in Proceedings of the 26th IEEE Photovoltaics Specialists Conference 287-290 (Anaheim, CA, USA, 1997).

9. Schermer, J. J. et al. Photon confinement in high-efficiency, thin-film III-V solar cells obtained by epitaxial lift-off. Thin Solid Films 511, 645-653 (2006)

10. Nakada, T. et al. Novel device structure for $\mathrm{Cu}(\mathrm{In}, \mathrm{Ga}) \mathrm{Se}_{2}$ thin film solar cells using transparent conducting oxide back and front contacts. Sol. Energy 77, 739-747 (2004).

11. Khrypunov, G. et al. Recent developments in evaporated CdTe solar cells. Sol. Energy Mater. Sol. Cell 90, 664-677 (2006).

12. Ito, S. et al. Bifacial dye-sensitized solar cell based on an ionic liquid electrolyte. Nat. Photon. 2, 693-698 (2008).

13. Cuevas, A. et al. 50 percent more output power from an albedo-collecting flat panel using bifacial solar cells. Sol. Energy 29, 419-420 (1982).

14. Asadpour, R. et al. Bifacial Si heterojunction perovskite organic-inorganic tandem to produce highly efficient $\left(\eta_{\mathrm{T}} \sim 33 \%\right)$ solar cell. Appl. Phys. Lett. 106, 243902 (2015).

15. Wang, J. et al. Photon energy upconversion through thermal radiation with the power efficiency reaching 16\%. Nat. Commun. 5, 5669 (2014).

16. Cannavale, A. et al. Perovskite photovoltachromic cells for building integration. Energy Environ. Sci. 8, 1578-1584 (2015).

17. Kim, B. J. et al. Highly efficient and bending durable perovskite solar cells: toward a wearable power source. Energy Environ. Sci. 8, 916-921 (2015).

18. Jeon, N. J. et al. Compositional engineering of perovskite materials for high-performance solar cells. Nature 517, 476-480 (2015).

19. Jeon, N. J. et al. Solvent engineering for high-performance inorganic-organic hybrid perovskite solar cells. Nat. Mater. 13, 897-903 (2014).

20. Burschka, J. et al. Sequential deposition as a route to high-performance perovskite-sensitized solar cells. Nature 499, 316-319 (2013).

21. Ahn, N. et al. Highly reproducible perovskite solar cells with average efficiency of $18.3 \%$ and best efficiency of $19.7 \%$ fabricated via Lewis base adduct of lead (II) iodide. J. Am. Chem. Soc. 137, 8696-8699 (2015).

22. Heo, J. H. et al. Hysteresis-less inverted $\mathrm{CH}_{3} \mathrm{NH}_{3} \mathrm{PbI}_{3}$ planar perovskite hybrid solar cells with $18.1 \%$ power conversion efficiency. Energy Environ. Sci. 8, 1602-1608 (2015).

23. Zhou, H. et al. Interface engineering of highly efficient perovskite solar cells. Science 345, 542-545 (2014). 
24. Shao, Y. et al. Origin and elimination of photocurrent hysteresis by fullerene passivation in $\mathrm{CH}_{3} \mathrm{NH}_{3} \mathrm{PbI}_{3}$ planar heterojunction solar cells. Nat. Commun. 5, 5784 (2014).

25. Ryu, S. et al. Fabrication of metal-oxide-free $\mathrm{CH}_{3} \mathrm{NH}_{3} \mathrm{PbI}_{3}$ perovskite solar cells processed at low temperature. J. Mater. Chem. A 3, 3271-3275 (2015).

26. Xu, J. et al. Perovskite-fullerene hybrid materials suppress hysteresis in planar diodes. Nat. Commun. 6, 7081 (2015).

27. Roldan-Carmona, C. et al. High efficiency single-junction semitransparent perovskite solar cells. Energy Environ. Sci. 7, 2968-2973 (2014).

28. Zhen, L. et al. Laminated carbon nanotube networks for metal electrode-free efficient perovskite solar cells. ACS Nano 8, 6797-6804 (2014).

29. Jiang, F. et al. Metal electrode-free perovskite solar cells with transfer-laminated conducting polymer electrode. Opt. Express 23, 83-91 (2015).

30. You, P. et al. Efficient semitransparent perovskite solar cells with grapheme electrodes. Adv. Mater. 27, 3632-3638 (2015).

31. Snaith, H. J. et al. Anomalous hysteresis in perovskite solar cells. J. Phys. Chem. Lett. 5, 1511-1515 (2015).

32. Loeper, P. et al. Organic-inorganic halide perovskite/crystalline silicon four-terminal tandem solar cells. Phys. Chem. Chem. Phys. 17, 1619-1629 (2015).

33. Kranz, L. et al. High-efficiency polycrystalline thin film tandem solar cells. J. Phys. Chem. Lett. 6, 2676-2681 (2015).

34. Wener, J. et al. Sputtered rear electrode with broadband transparency for perovskite solar cells. Sol. Energy Mater. Sol. Cell 141, 407-413 (2015).

35. Bailie, C. D. et al. Semi-transparent perovskite solar cells for tandems with silicon and CIGS. Energy Environ. Sci. 8, 956-963 (2015).

36. Guo, F. et al. High-performance semitransparent perovskite solar cells with solution-processed silver nanowires as top electrodes. Nanoscale 7, 1642-1649 (2015).

37. Liu, D., Gangishetty, M. K. \& Kelly, T. L. Effect of $\mathrm{CH}_{3} \mathrm{NH}_{3} \mathrm{PbI}_{3}$ thickness on device efficiency in planar heterojunction perovskite solar cells. J. Mater. Chem. A 2, 19873-19881 (2014).

38. Ke, W. et al. Efficient hole blocking layer-free planar halide perovskite thin-film solar cells. Nat. Commun. 6, 6700 (2015).

39. Wu, Y. et al. Retarding the crystallization of $\mathrm{PbI}_{2}$ for highly reproducible planar-structured perovskite solar cells via sequential deposition. Energy Environ. Sci. 7, 2934-2938 (2014).

40. Chen, Y. et al. Layer-by-layer growth of $\mathrm{CH}_{3} \mathrm{NH}_{3} \mathrm{PbI}_{3-\mathrm{x}} \mathrm{Cl}_{\mathrm{x}}$ for highly efficient planar heterojunction perovskite solar cells. Adv. Mater. 27, 1053-1059 (2015).

41. Fu, F. et al. Controlled growth of $\mathrm{PbI}_{2}$ nanoplates for rapid preparation of $\mathrm{CH}_{3} \mathrm{NH}_{3} \mathrm{PbI}_{3}$ in planar perovskite solar cells. Phys. Status Solidi A doi:1002/pssa.201532442 (2015).

42. Lee, Y. H. et al. Unraveling the reasons for efficiency loss in perovskite solar cells. Adv. Energy Mater. 25, 3925-3933 (2015).

43. Lee, Y. H. et al. Controllable self-induced passivation of hybrid lead iodide perovskites toward high performance solar cells. Nano Lett. 14, 4158-4163 (2014).

44. Maiberg, M. et al. Theoretical study of time-resolved luminescence in semiconductors. II. Pulsed excitation. J. Appl. Phys. 116, 123711 (2014).

45. Metzger, W. K. et al. Analysis of charge separation dynamics in a semiconductor junction. Phys. Rev. B. 71, 035301 (2005).
46. Koida, T. et al. Hydrogen-doped $\operatorname{In}_{2} \mathrm{O}_{3}$ as hihg-mobility transparent conductive oxide. Jpn J. Appl. Phys. 46, L685-L687 (2007).

47. Jäger, T. et al. Hydrogenated indium oxide window layers for high-efficiency $\mathrm{Cu}(\mathrm{In}, \mathrm{Ga}) \mathrm{Se}_{2}$ solar cells. J. Appl. Lett. 117, 205301 (2015).

48. Jäger, T. et al. Improved open-circuit voltage in $\mathrm{Cu}(\mathrm{In}, \mathrm{Ga}) \mathrm{Se}_{2}$ solar cells with high work function transparent electrodes. J. Appl. Lett. 117, 225303 (2015).

49. Chirila, A. et al. Highly efficient $\mathrm{Cu}(\mathrm{In}, \mathrm{Ga}) \mathrm{Se}_{2}$ solar cells grown on flexible polymer films. Nat. Mater. 10, 857-861 (2011).

50. Yang, Y. et al. Multilayer transparent top electrode for solution processed perovskite/Cu(In, Ga)(Se, S) ${ }_{2}$ four terminal tandem solar cell. ACS Nano 9, 7714-7721 (2015).

51. Mailoa, J. et al. A 2-terminal perovskite/silicon multijunction solar cell enabled by a silicon tunnel junction. Appl. Phys. Lett. 106, 121105 (2015).

52. Chen, C. et al. Perovskite/polymer monolithic hybrid tandem solar cells utilizing a low-temperature, full solution process. Mater. Horiz. 2, 203-211 (2015).

\section{Acknowledgements}

Financial funding from Swiss National Science Foundation (SNF)-NRP70, PV2050 (project no.: 407040_153976 and 407040_153916), SNF-NanoTera and Swiss Federal Office of Energy (SYNERGY: 20NA21_150950), as well as Competence Center for Energy and Mobility (project CONNECT PV) are gratefully acknowledged. F.F. thanks the financial support from the Chinese Scholarship Council (CSC).

\section{Author contributions}

F.F., S.B. and A.N.T. designed the research and experiments; F.F., T.F., T.J. and A.E. fabricated the perovskite solar cells and CIGS solar cells; F.F., T.F., T.J., E.A., B.B., S.Y., S.B. and A.N.T. performed the characterization and analysis; F.F., S.B. and A.N.T. wrote the paper; all authors contributed to discussions.

\section{Additional information}

Supplementary Information accompanies this paper at http://www.nature.com/ naturecommunications

Competing financial interests: The authors declare no competing financial interests.

Reprints and permission information is available online at http://npg.nature.com/ reprintsandpermissions/

How to cite this article: Fu, F. et al. Low-temperature-processed efficient semi-transparent planar perovskite solar cells for bifacial and tandem applications. Nat. Commun. 6:8932 doi: 10.1038/ncomms9932 (2015).

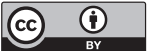

This work is licensed under a Creative Commons Attribution 4.0 International License. The images or other third party material in this article are included in the article's Creative Commons license, unless indicated otherwise in the credit line; if the material is not included under the Creative Commons license, users will need to obtain permission from the license holder to reproduce the material. To view a copy of this license, visit http://creativecommons.org/licenses/by/4.0/ 